\title{
Mapping of Soil Salinity Using Electromagnetic Induction: A Case Study of East Nile Delta, Egypt
}

\author{
A. M. Saleh, A. B. Belal and E. S. Mohamed \\ Soil Science Dept., National Authority for Remote Sensing and Space Sciences \\ (NARSS), Cairo, Egypt
}

\begin{abstract}
$\mathbf{T}$
HE OBJECTIVE of this study is to map the spatial distribution of the soil salinity at field scale for site-specific management using the electromagnetic sensor (Geonics EM38). The salinity of an area of 67.2 ha cultivated wheat pivot field at East of Nile Delta, Egypt, was analyzed by reading the apparent soil electric conductivity (ECa) using the EM38 sensor at 432 locations within the pivot field. Twenty soil sampling sites were chosen according to spatial response surface sampling design (SRS). At those sites, soil core samples were taken at $0.3 \mathrm{~m}$ intervals to a depth of $0.9 \mathrm{~m}$. Four soil variables were analyzed which are soil salinity (ECe), soil clay content (clay), soil water content (WC), and soil organic matter (OM). The multiple linear calibration model (MLC) was used to predict the depth-specific soil salinity ECe values at the remaining non-sampled locations. The MLC calibration model predicted ECe from EM38 signal readings with $\mathrm{R}^{2}$ ranging from 0.41 to 0.73 for the multiple-depth profile. Furthermore, the MLC model provided field range estimates of soil salinity. Ninety-one percent of the field had ECe values below $4 \mathrm{dS} \mathrm{m}^{-1}$. The obtained salinity maps were helpful to display the spatial patterns of soil salinity for site-specific management.
\end{abstract}

Keywords : Soil salinity, Electromagnetic induction, Spatial response surface sampling design, Multiple linear calibration model, East Nile Delta.

\section{Introduction}

The soil apparent electrical conductivity (ECa) has a great potential for characterizing the soil limiting parameters (Mann et al., 2011 and Moral et al., 2010). The ECa correlates with various soil properties such as salinity (Rhoades et al., 1999), clay content (Triantafilis \& Lesch, 2005 and Wuddivira et al., 2012), water content (Haimelin, 2008) and carbon content (Martinez et al., 2009). The ECa can be used as an indirect indicator for identifying some important soil properties including soil salinity, clay content, cation exchange capacity, soil moisture content, and temperature (McNeill, 1992 and Rhoades et al., 1999).

Electromagnetic induction (EMI) sensors noninvasively measure the spatial variations of soil apparent electric conductivity (Atwell et al., 2013; Bréchet et al., 2012 Rossi et al., 2013 and Wuddivira et al., 2012). Electromagnetic induction methods are much less labor, cost and time intensive as the volume of measurement is larger than traditional point soil sampling (Rhoades et al., 1999). The most of the EC signal is related to concentration of soluble salts in salt-affected soils, while, the EC variations are related to soil texture, organic matter, moisture content and cation exchange capacity in non-saline soils (McNeill, 1992; Rhoades et al., 1999 and Lund et al., 2001). Response surface soil sampling design is closely related area of statistical research studied specifically from the viewpoint of model estimation (Myers and Montgomery 2002). Lesch (2005) revealed that the response surface sampling design can outperform the probability based sampling technique with respect to some important model based prediction criteria, particularly optimal estimation of the fixed-effect part of a spatial linear model.

The soil salinity calibration model is an empirical spatially referenced regression model that includes the soil property being calibrated with ECa and trend surface parameters and takes into account the uncertainty of the variables and thus the predictions are probability distributions 
of the possible values (Corwin and lesch, 2005; Douaik et al., 2009). Only a limited number of samples are needed for the model calibration in this model-based approaches, compared to the designed-based sampling approaches to obtain the same level of the regression model accuracy. The objective of this study is to map the spatial distribution of the soil salinity at field scale for sitespecific management using the electromagnetic sensor (Geonics EM38).

\section{Materials and Methods}

\section{Site selection}

An irrigated pivot field in Sixths of October Company for Agricultural Projects (SOAP) which located in El-Salhia Area, East of Nile Delta, Egypt was selected for soil salinity modeling (Fig. 1). It is bounded by $31^{\circ} 58^{\prime} 30^{\prime \prime}$ and $31^{\circ} 59^{\prime}$ $05^{\prime \prime}$ longitudes and $30^{\circ} 25^{\prime} 55^{\prime \prime}$ and $30^{\circ} 26^{\prime} 30^{\prime \prime}$ latitudes with a total area of 154 feddan.

\section{Electromagnetic survey and analyses}

The apparent soil conductivity (ECa) of the pivot field was measured using Electromagnetic Induction (EM38) sensor (Geonics Ltd., Mississauga, Ontario, Canada) in millisiemens per meter $(\mathrm{mS} / \mathrm{m})$ at each coil separation In-phase response in parts per thousand (ppt) of secondary to primary magnetic field at each coil separation before wheat planted. A number of 432 EM38 survey readings were measured vertically and horizontally along 10 transects grid across the pivot study area with 90 meters averaged distance between each transect. The readings were performed few days before tillage and planting and after an irrigation event where the soil water content was close to the field capacity. The maximum normalized residual test was applied to EM38 signal data for outlier's existence (Iglewicz and Hoaglin, 1993).

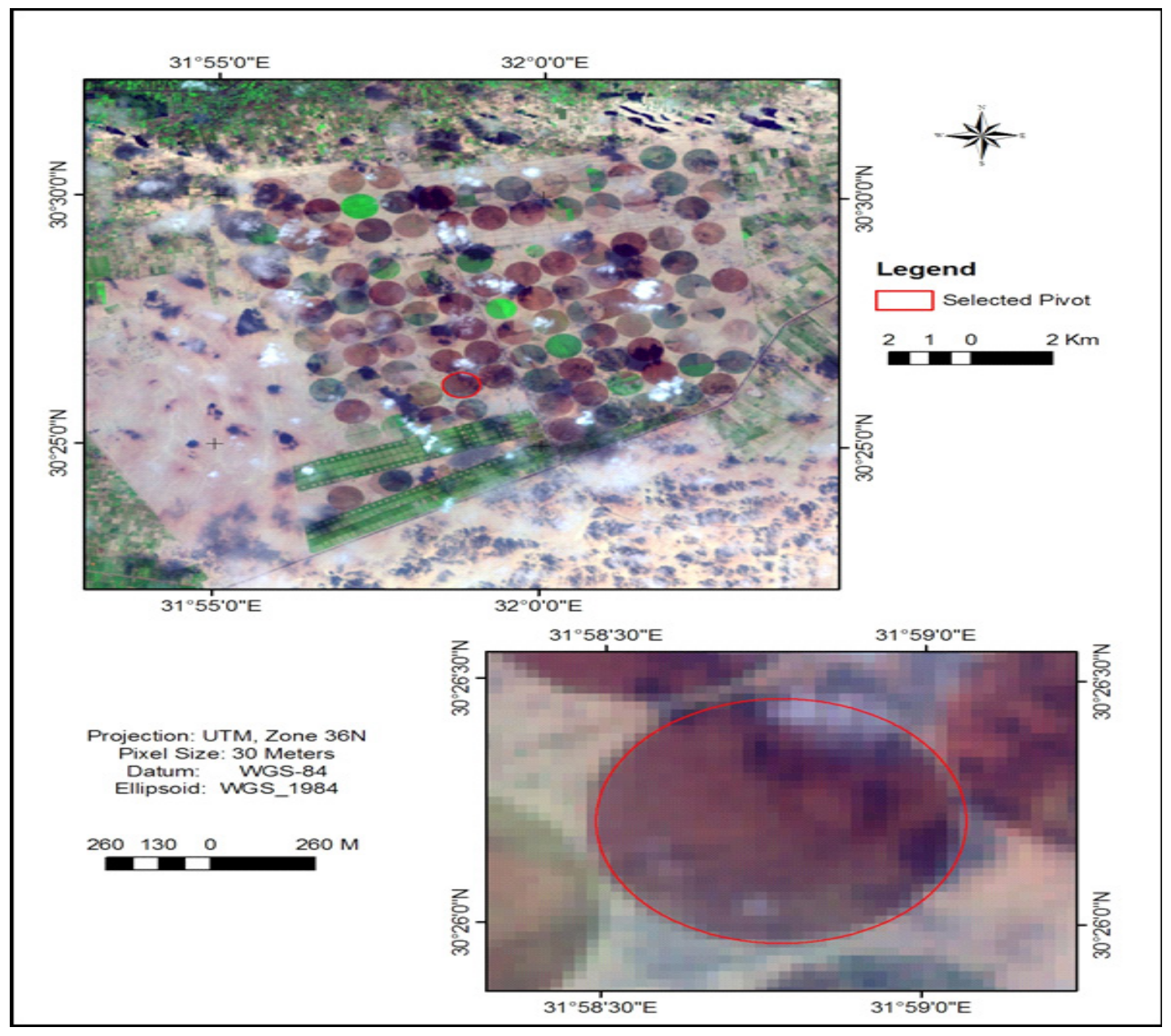

Fig. 1. The selected pivot for study area 


\section{Soil sampling and analyses}

A spatial response surface design (SRS) (Corwin and lesch, 2005) was used to locate the best locations for soil sampling. Twenty soil sampling sites were located according to the selected SRS sampling design. Four soil variables were chosen for the selected SRS sampling sites which are soil salinity (ECe, dS/m), soil texture (clay, \%), soil water content (WC, \%), and soil organic matter (OM, \%) at $30 \mathrm{~cm}$ depth intervals to a maximum depth of $90 \mathrm{~cm}(0-30,30-60$, and 60$90 \mathrm{~cm}$ ). The soil samples were air-dried, crushed softly, and passed through a 2-mm sieve to get the "fine earth." The fine earth was analyzed in the laboratory according to (Soil Survey Staff, 2014).

\section{Soil salinity calibration Modelling}

A multiple linear calibration model (MLC) was performed to predict the soil electric conductivity levels within the pivot field using the EM38 signal readings. The soil variable which has the most strength of the relationship against the standard variables (EM38 signal data (z1), the secondary (z2) EM38 signal data, and both the $\mathrm{X}$ and $\mathrm{Y}$ survey coordinates) was chosen as the soil variable for the model. The all possible model combinations were analyzed and the model with the lowest prediction errors was chosen as the more accurate model.

\section{Soil salinity mapping}

Interpolation between sampling locations was made by ordinary Kriging (Deutsch and Journel, 1992) interpolation method using ArcMap 10.2 (ESRI, 2013). Ordinary Kriging was used to estimate the value of a continuous characteristic $\mathrm{z}$ at a non-sampled locations (u) using only the data on this characteristic $[\mathrm{z}$ (ua), $\alpha=1, \ldots, \mathrm{n}]$ as a linear combination of neighboring observations.

\section{$\underline{\text { Results and Discussion }}$}

\section{EM data description}

The obtained EM38 readings in the study pivot were subjected to descriptive statistical analyses. The statistical analyses results (Table 1) showed that, for the EM vertical readings (EMV) the data ranged between 12.00 and 333.00 with a mean of 64.35 and standard error of 2.79, also the lower and upper bounds of $95 \%$ Confidence Interval for Mean are 58.86 and 69.83 , respectively. While for the EM horizontal readings (EMh), the data ranged between 10.00 and 239.00 with a mean of 45.11 and standard error of 1.85 , also the lower and upper bounds of $95 \%$ Confidence Interval for Mean are 41.48 and 48.75 , respectively. The data range for EMv and EMh readings was 321.00 and 229.00 , respectively. The results of variance are 3362.86 and 1479.46 for EMv and EMh readings respectively. Also, the standard deviation (SD) results are 57.99 and 38.46 for EMv and EMh readings, respectively. From percentiles and quartiles analyses, it appears that $50 \%$ of EM readings lie between 12.00 and 36.50 for EMv readings and 10.00 and 28.00 for EMh readings, while $95 \%$ of EM readings lie between 12.00 and 187.35 for EMv readings and 10.00 and 125.35 for EMh readings. The frequency distributions for EMv and EMh readings indicate that both vertical and horizontal EM readings follow nearly a bellshaped Gaussian distribution as about $84.72 \%$ and $85.65 \%$ of EMv and EMh readings, respectively lie within one standard deviation of the mean.

\section{Soil variables}

Four soil variables were chosen for the selected SRS sampling sites (Fig. 2). The considered soil variables are soil salinity $(\mathrm{ECe}, \mathrm{dS} / \mathrm{m})$, soil texture (clay, \%), soil water content (WC, \%), and soil organic matter (OM, \%) at $30 \mathrm{~cm}$ depth intervals to a maximum depth of $90 \mathrm{~cm}$. The statistical analyses of the soil variables (Table 2) show that the coefficients of variation (CV) of ECe were very high thus confirming the large variability in soil salinity within the pivot. In contrast, the coefficients variation of soil water content are the lowest of the four variables.

\section{Soil salinity calibration modeling}

A multiple linear calibration model was performed to predict the soil salinity levels within the pivot field using the EM38 survey readings acquired across the pivot. The correlation results (Table 3) between the sampled soil variables and the regression variables (the primary (z1) EM38 signal data, the secondary (z2) EM38 signal data, and both the $\mathrm{X}$ and $\mathrm{Y}$ coordinates) by depth showed that, the soil variable salinity is more correlated with the variables $\mathrm{Z} 1$ and $\mathrm{Y}$ than other soil variables. The OM soil variable is the poorest correlated variable while clay content and water content soil variables are similar in their relationship with the variables. The soil variables have a weak relationship with both $\mathrm{z} 1$ and $\mathrm{X}$ variables. The correlation between soil salinity variable with variables $\mathrm{Z} 1$ and $\mathrm{Y}$ other than the other variables shows that this variable is the appropriate variable for the soil salinity calibration model. 
TABLE 1. Descriptive statistics of EM readings

\begin{tabular}{|c|c|c|c|c|c|}
\hline \multirow{2}{*}{ Statistic } & \multicolumn{2}{|c|}{ Reading } & \multirow{2}{*}{ Statistic } & \multicolumn{2}{|c|}{ Reading } \\
\hline & EMv & EMh & & EMv & EMh \\
\hline Mean & 64.35 & 45.11 & Variance & 3362.86 & 1479.46 \\
\hline Confidence $-95 \%$ & 58.86 & 41.48 & Std.Dev. & 57.99 & 38.46 \\
\hline Confidence $+95 \%$ & 69.83 & 48.75 & Confidence SD -95\% & 54.36 & 36.06 \\
\hline Median & 36.50 & 28.00 & Confidence SD +95\% & 62.14 & 41.22 \\
\hline Minimum & 12.00 & 10.00 & Coef.Var. & 90.12 & 85.26 \\
\hline Maximum & 333.00 & 239.00 & Standard Error & 2.79 & 1.85 \\
\hline Skewness & 1.90 & 2.05 & Lower Quartile & 26.00 & 20.00 \\
\hline Std.Err. Skewness & 0.12 & 0.12 & Upper Quartile & 87.00 & 59.00 \\
\hline Kurtosis & 3.87 & 4.93 & Range & 321.00 & 229.00 \\
\hline Std.Err. Kurtosis & 0.23 & 0.23 & Quartile Range & 61.00 & 39.00 \\
\hline
\end{tabular}

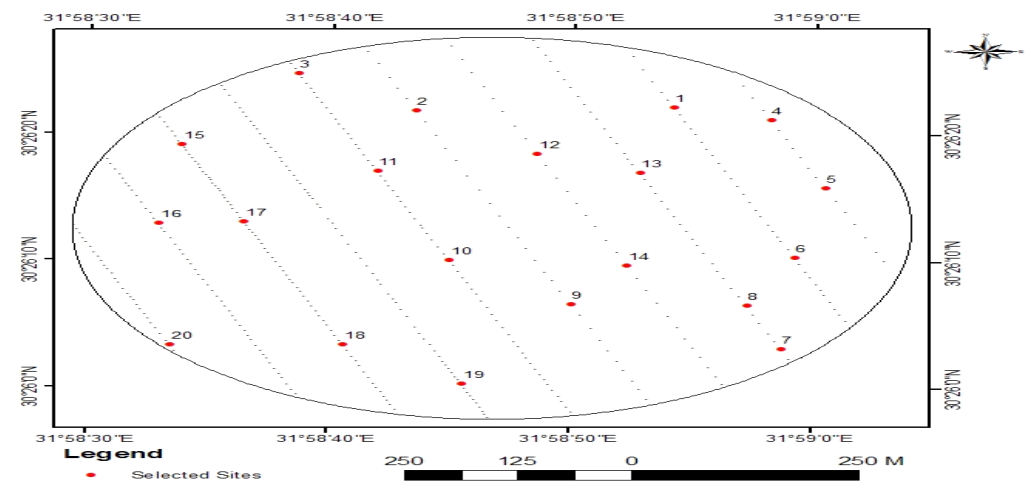

Fig.2. Selected SRS soil sampling sites

TABLE 2. Statistical analyses of the four soil variables

\begin{tabular}{|c|c|c|c|c|c|c|c|c|c|c|c|c|c|}
\hline $\begin{array}{c}\text { Soil } \\
\text { variable }\end{array}$ & $\begin{array}{l}\text { Depth } \\
\text { level }\end{array}$ & Mean & $\begin{array}{l}\text { std. } \\
\text { dev }\end{array}$ & $\begin{array}{l}\text { CV } \\
\%\end{array}$ & $\min$ & $\max$ & $\begin{array}{c}\text { Soil } \\
\text { variable }\end{array}$ & $\begin{array}{l}\text { Depth } \\
\text { level }\end{array}$ & mean & $\begin{array}{l}\text { std. } \\
\text { dev }\end{array}$ & $\begin{array}{l}\text { CV } \\
\%\end{array}$ & $\min$ & $\max$ \\
\hline \multirow{3}{*}{$\mathrm{ECe}$} & 30 & 1.617 & 1.811 & 112.00 & 0.21 & 5.98 & \multirow{3}{*}{ WC } & 30 & 0.174 & 0.029 & 16.67 & 0.13 & 0.22 \\
\hline & 60 & 2.542 & 2.347 & 92.33 & 0.34 & 6.95 & & 60 & 0.169 & 0.032 & 18.93 & 0.12 & 0.23 \\
\hline & 90 & 2.227 & 2.167 & 97.31 & 0.19 & 6.38 & & 90 & 0.162 & 0.031 & 19.14 & 0.12 & 0.22 \\
\hline \multirow{3}{*}{$\%$ Clay } & 30 & 11.588 & 4.497 & 38.81 & 5.15 & 19.15 & \multirow{3}{*}{$\mathrm{OM}$} & 30 & 0.397 & 0.074 & 18.64 & 0.269 & 0.538 \\
\hline & 60 & 10.778 & 4.596 & 42.64 & 4.75 & 18.83 & & 60 & 0.172 & 0.114 & 66.28 & 0.076 & 0.538 \\
\hline & 90 & 9.817 & 4.306 & 43.86 & 4.55 & 18.17 & & 90 & 0.138 & 0.114 & 82.61 & 0.042 & 0.454 \\
\hline
\end{tabular}

Egypt. J. Soil Sci. 57, No. 2 (2017) 
TABLE 3. Correlation coefficients between soil and regression variables

\begin{tabular}{|c|c|c|c|c|c|}
\hline Soil variable & Depth $(\mathbf{c m})$ & $\mathbf{Z 1}$ & $\mathbf{Z 2}$ & $\mathbf{X}$ & $\mathbf{Y}$ \\
\hline \multirow{3}{*}{ EC } & 30 & 0.76 & 0.19 & 0.15 & -0.85 \\
\cline { 2 - 6 } & 60 & 0.67 & 0.31 & 0.36 & -0.71 \\
\cline { 2 - 6 } & 90 & 0.60 & 0.07 & 0.10 & -0.63 \\
\hline \multirow{3}{*}{ Clay } & 30 & 0.60 & 0.12 & 0.42 & -0.41 \\
\cline { 2 - 6 } & 60 & 0.51 & 0.15 & 0.42 & -0.33 \\
\cline { 2 - 6 } & 90 & 0.56 & 0.18 & 0.49 & -0.43 \\
\cline { 2 - 6 } & 30 & 0.66 & 0.10 & 0.37 & -0.48 \\
\cline { 2 - 6 } & 60 & 0.56 & 0.17 & 0.39 & -0.37 \\
\hline \multirow{3}{*}{ WC } & 90 & 0.58 & 0.17 & 0.45 & -0.44 \\
\cline { 2 - 6 } & 30 & 0.04 & 0.20 & 0.22 & 0.04 \\
\cline { 2 - 6 } & 60 & -0.17 & -0.31 & -0.04 & 0.08 \\
\hline
\end{tabular}

The results of the calibration model parameters combinations analyses indicated that, the $\mathrm{Z1} / \mathrm{Y}$ parameters combination is the combination which produced the more accurate calibration model. The resulted calibration model for predicting soil salinity within the pivot field using the EM38 conductivity survey readings is in the form :

where :

$$
\ln (\mathrm{ECe})=\mathrm{b} 0+\mathrm{b} 1(\mathrm{Z} 1)+\mathrm{b} 2(\mathrm{Y})
$$

ECe is the soil salinity,

$\mathrm{Z} 1$ and $\mathrm{Y}$ are the model variables and

b0, b1, and b2 are model parameters

The calibration model was fitted to the bulk average, in addition to fitting to each set of depth values. The calibration model summary statistics for each fitted depth are shown in Table 4.

TABLE 4. Calibration model Summary Statistics

\begin{tabular}{|c|c|c|c|}
\hline Depth & R-square & $\begin{array}{c}\text { Root } \\
\text { MSE }\end{array}$ & $\begin{array}{c}\text { Est. } \\
\mathbf{\% C V}\end{array}$ \\
\hline $30 \mathrm{~cm}$ & 0.73 & 0.60 & 66.44 \\
\hline $60 \mathrm{~cm}$ & 0.51 & 0.85 & 103.41 \\
\hline $90 \mathrm{~cm}$ & 0.41 & 1.02 & 135.73 \\
\hline Bulk average & 0.53 & 0.80 & 94.60 \\
\hline
\end{tabular}

The $\mathrm{R}^{2}$ values of the calibration models for the different soil sampling depths and the bulk average ranged between 0.41 for $90 \mathrm{~cm}$ soil depth and 0.73 for $30 \mathrm{~cm}$ soil depth. The $\mathrm{R}^{2}$ is being significant at $\mathrm{P}<0.001$ for the $30 \mathrm{~cm}$ depth and significant at $\mathrm{P}<0.01$ for the remaining sampling depths and bulk average. Thus, the calibration model accounted for $41 \%$ to $73 \%$ of the observed salinity variability at the different sampling depths. The pivot field salinity was interpolated between sampling locations for the specified sampling depths by ordinary kriging interpolation technique. The spatial distribution of soil salinity for the specified sampled soil depths are shown in Fig. 3.

\section{Conclusions}

The EM38 sensor provided non-invasive measurements of the apparent electrical conductivity (ECa) with less labor, cost and time intensive over other conductivity methods. The spatial response surface (SRS) sampling design allowed minimizing the number of samples required number of soil samplings to only a small set of 20 soil sampling sites to optimally estimate the spatially referenced regression model between the EM apparent electric conductivity (ECa) and the sampled soil electric conductivity. The sampled soil salinity correlated linearly with the EM signal data and indicated the incorporation of the trend surface parameters in the calibration modeling. The multiple linear calibration (MLC) model proved to be reliable for predicting the soil salinity at the field scale for site-specific management.

\section{Acknowledgement}

The authors of this research acknowledge the Science and Technology Development Fund (STDF), Egypt for the financial support and also acknowledge the Sixths of October Company for Agricultural Projects (SOAP) for the facilitation of conducting this research work. The authors also acknowledge the National Authority for Remote Sensing and Space Sciences (NARSS) for providing all the supporting material for this research work. 


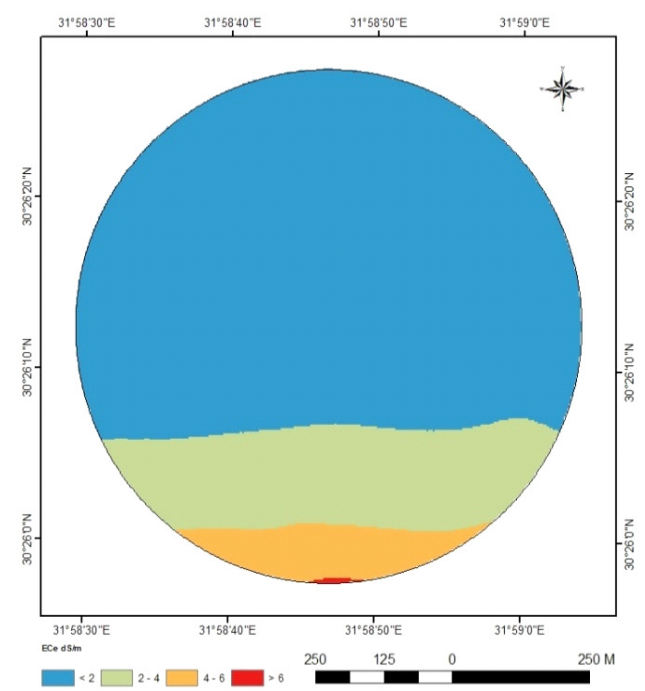

Mapped soil salinity at $30 \mathrm{~cm}$ depth

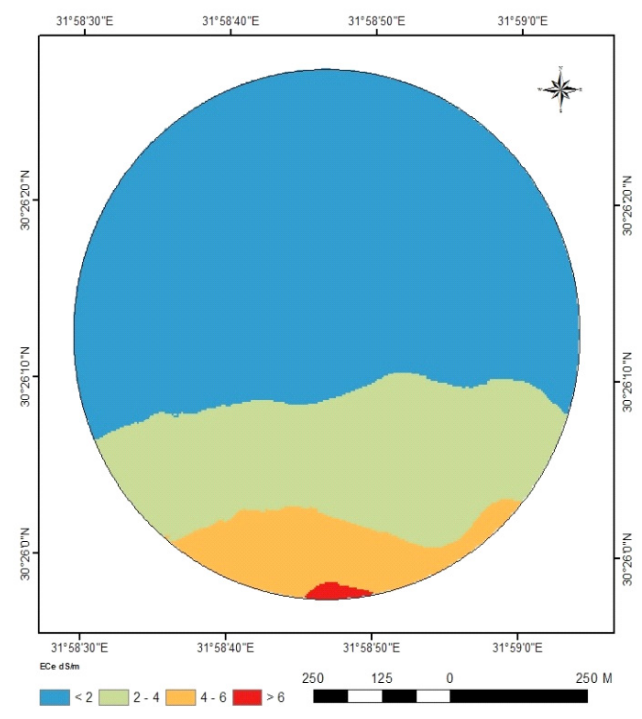

Mapped soil salinity at $90 \mathrm{~cm}$ depth

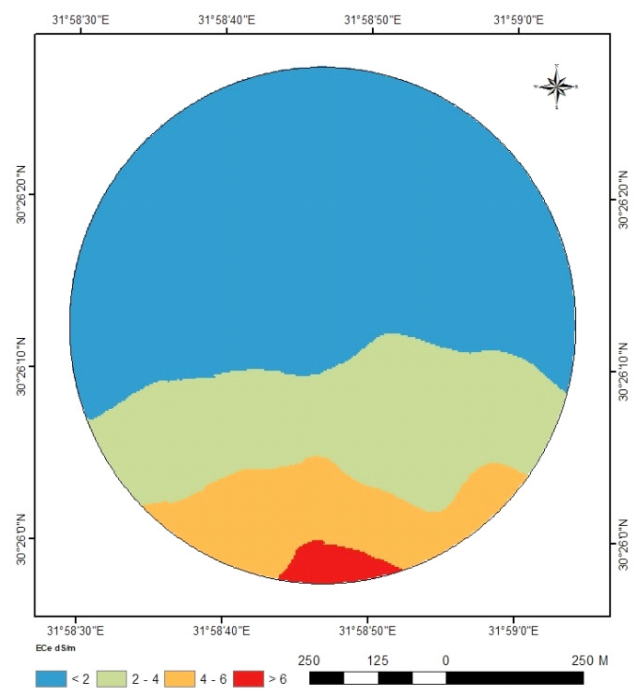

Mapped soil salinity at $60 \mathrm{~cm}$ depth

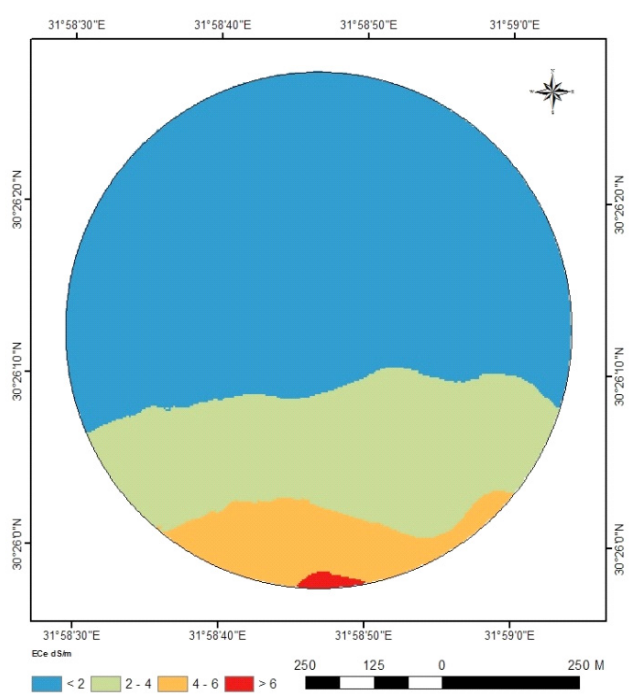

Mapped soil salinity (bulk avarage)

Fig. 3. Soil salinity maps at sampled depths

\section{References}

Atwell M., Wuddivira M., Gobin J., and Robinson D. (2013) Edaphic controls on sedge invasion in a tropical wetland assessed with electromagnetic induction. Soil Sci. Soc. Amer. J., 77, 1865-1874.

Bréchet L., Oatham M., Wuddivira M., and Robinson D.A. (2012) Determining spatial variation in soil properties in teak and native tropical forest plots using electromagnetic induction. Vadose Zone J., 11, DOI:10.2136/vzj2011.0102.
Corwin, D.L., and Lesch, S.M. (2005) Characterizing soil spatial variability with apparent soil electrical conductivity. I. Survey protocols. Comput. Electron. Agric., 46, 103-134.

Deutsch, C. V. and Journel, A. G. (1992) GSLIB: Geostatistical Software Library and User's Guide. Oxford University Press, New York.

Douaik, A., Meirvenne, M. V., and Tóth T. (2009) Stochastic approaches for space-time modeling and interpolation of soil salinity. In: Metternicht,

Egypt. J. Soil Sci. 57, No. 2 (2017) 
G. and Zinck, J. A. (Ed.). Remote Sensing of Soil Salinization: Impact on Land Management. Taylor and Francis Group, LIC.

ESRI(2013) ArcGIS Desktop: Release 10.2. Redlands, CA, USA.

Haimelin R. (2008) Mapping soil water content on agricultural fields using electromagnetic induction. Report. Helsinki Universty of Technology, Helsinki.

Iglewicz, B. and Hoaglin, DC. (1993) How to Detect and Handle Outliers. Asqc Basic References in Quality Control, vol 16. American Society for Quality Control.

Lesch, S. M. (2005) Sensor-directed surface response sampling design for characterizing spatial variation in soil properties. Comp Electron. Agric.

Lund, E. D., Wolcott, M. C. and Hanson, G. P. (2001) Applying Nitrogen Site-Specifically Using Conductivity Maps and Precision Agriculture Technology. $2^{\text {nd }}$ International Nitrogen Conference in Science and Policy. Potomac, MD, USA.

Mann, K.K., Schumann, A.W., and Obreza, T.A. (2011) Delineating productivity zones in a citrus grove using citrus production, tree growth and temporally stable soil data. Prec. Agri., 12, 457-472.

Martinez G., Vanderlinden K., Ordóñez R., and Muriel J.L. (2009) Can apparent electrical conductivity improve the spatial characterization of soil organic carbon? Vadose Zone J., 8, 586-593.

McNeill, J.D. (1992) Rapid, accurate mapping of soil salinity by electromagnetic ground conductivity meters, Advances in Measurements of Soil Physics Properties: Bringing Theory into Practice, Soil Science Society of America Special Publication 30, American Society of Agronomy, Crop Science Society of America and Soil Science Society of America, Madison, Wisconsin, pp. 201-229

Moral, F.J., Terrón, J.M. and Silva, J.R. (2010) Delineation of management zones using mobile measurements of soil apparent electrical conductivity and multivariate geostatistical techniques. Soil Till. Res. 106, 335-343.

Myers, R. H., and Montgomery, D. C. (2002) Response surface methodology: process and product optimization using designed experiments $\left(2^{\text {nd }} e d.\right)$.
New York, NY: Wiley.

Rhoades J.D. and Chanduvi F., (1999) Soil salinity assessment: Methods and interpretation of electrical conductivity measurements. FAO, 57, 1-150.

Rossi R., Amato M., Bitella G. and Bochicchio R. (2013) Electrical resistivity tomography to delineate greenhouse soil variability. Int. Agrophys., 27, 211 218.

Soil Survey Staff (2014) Soil Survey Field and Laboratory Methods Manual. Soil Survey Investigations Report No. 51, Version 2.0. Manual, Natural Resources Conservation Service, U.S.

Triantafilis, J. and Lesch, S.M. (2005) Mapping clay content variation using electromagnetic induction techniques. Comp. Elec. Agri. 46, 203-237.

Wuddivira, M.N., Robinson, D. A., Lebron, I., Bréchet L., Atwell, M., De Caires, S., Oatham, M., Jones , S.B., Abdu, H. Verma, A.K. and Tuller M. (2012) Estimation of soil clay content from hygroscopic water content measurements. Soil Sci. Soc. Am. J., 76, 1529-1535.

(Received: 1/2/2016; accepted:17/2/2016) 


\title{
تخريط ملوحة التربة باستخدام الحث الكهرومغتاطيسي بمنطقة شرق الالتا ـ مصر

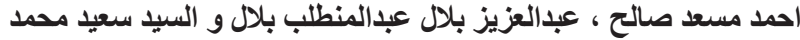

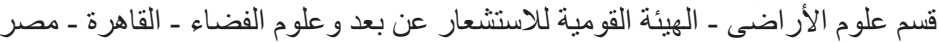

\begin{abstract}
الهدف من البحث هو استخدام مستشعر الحث الكهرومغنطبسى لانتاج خريطة توزيع ملوحة التربة علي مستي مستوي

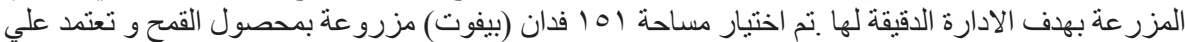

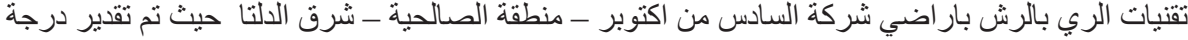

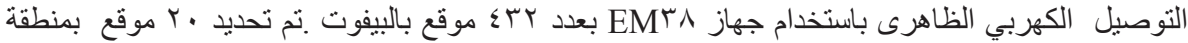

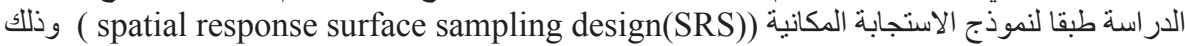

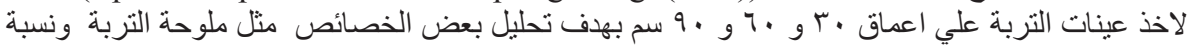

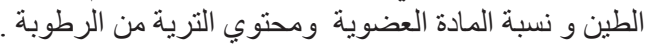

وقد تم استخدام نموذج المعايرة الخطي المتعدد (multiple linear calibration model (MLC) للتنبؤ

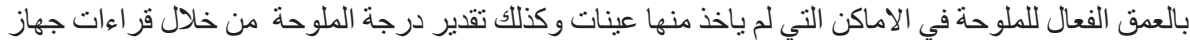
عMr^

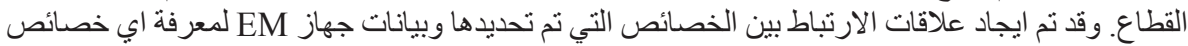

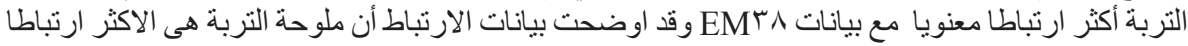

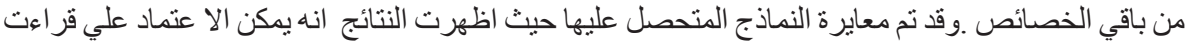

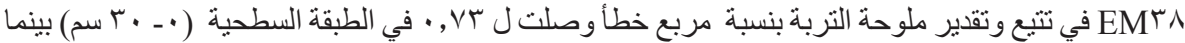

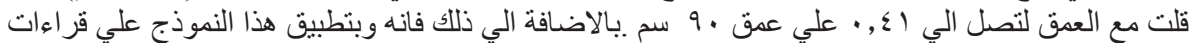

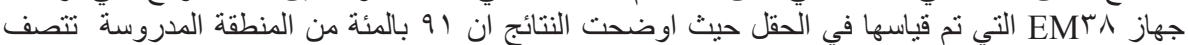

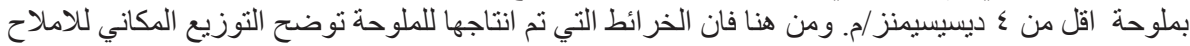

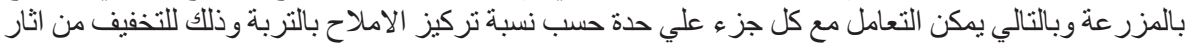

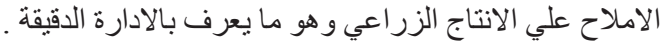

